\title{
O Sacrifício Asteca nos Primeiros Cronistas
}

\author{
Luiz Antônio Lindo(*)
}

Resumo: O sacrifício humano entre os astecas é um assunto recorrente nos relatos dos primeiros cronistas. Este artigo procura apresentar um panorama desse tipo de morte ritual tal como ele é referido em vários textos de cronistas da primeira hora da conquista. A seleção de trechos obedeceu ao critério do valor informativo.

Palavras-chave: Sacrifício Humano, Astecas, Cronistas.

\begin{abstract}
The human sacrifice among the aztecs appears in the early american chroniclers as a recurrent subject. This paper intends to give an account of this kind of ritual killing as long as it presents itself in the multiple texts related to the time of the American conquer. The choice of the passages was done according to their informative value.
\end{abstract}

Keywords: Human Sacrifice, Aztecs, Early American Chroniclers.

(*) Professor da Faculdade de Filosofia, Letras e Ciências Humanas - FFLCH/USP e do Programa de Pós-graduação em Integração da América Latina _ Prolam/USP. E-mail: lal@usp.br. Recebido em: 11.11.2009 e aceito em: 19.3.2010. 


\section{INTRODUÇÃo}

Sacrificium, "sacrifício"; junto a sacrifico (de sacrum facere), "oferecer um sacrifício"; por meio de sacrum, "toda espécie de coisa sagrada” ou "o que não pode ser tocado sem ser sujado ou sujar”, em oposição a profano (Ernout/Meillet, Dictionnaire Étymologique de la Langue Latine). De etimologia incerta, especula-se sobre a família de sacer,-cra, -crum provir de *sak-(Walde/Hofmann, Lateinisches Etymologisches Wörterbuch). No latim e nas suas cercanias (osco, umbro, sabino), a raiz gerou uma grande variedade de termos (J. Pokorny, Indogermanisches Etymologisches Wörterbuch, t. III), os quais passaram por elos naturais às línguas românicas e modernas. No alemão, o correspondente Opfer é considerado uma construção nativa, a partir do verbo opfern, (F. Kluge, Etymologisches Wörterbuch der deutschen Sprache), conquanto se dispute uma possível origem desde offerre ou operari. Os gregos antigos costumavam empregar a propósito thysia, termo geral usado, de preferência, no plural, já que não contavam para tanto com um termo uniforme. A raiz em latim aponta para um significado primário de "sagrado”, o que é pouco comum nesse nível semântico, já que se parte diretamente para esse sentido sem fazer referência prévia a entes concretos, cuja percepção sensória geralmente assinala a precedência na formação dos vocábulos.

No sacrifício de sangue, um ser vivo é executado por um sacerdote (huic deo sacrificatur, VARRÃO, L. 6,16) e consagrado a uma divindade. A vítima é, assim, entregue e entrega por sua vez, a própria vida. Quanto mais alta a vítima na escala natural, maior o sacrifício, como assinalou Lívio, que, a propósito dum episódio referente à administração no Oriente, relata o cuidado dos senadores romanos em verem sacrificadas aos deuses as vítimas maiores: Priorum prodigiorum causa senatus censuerat, ut consules majoribus hostiis, quibus diis videretur, sacrificarent. (Liv. 32,1,13) $)^{(1)}$. Por esse critério, o último grande palco para esse tipo de ritual de morte foi montado na América, onde, até princípios do século XVI, bandos de vítimas humanas eram os seus protagonistas.

\section{O SACRIFÍCIO ASTECA}

Os astecas foram devotadíssimos praticantes do sacrifício humano. "El empleo más importante del sacerdocio, la principal función del culto de los mexicanos, eran los sacrificios que hacían, ya para obtener alguna gracia del cielo, ya para darle gracias por los beneficios recibidos”, observa Robelo(2), repisando as palavras de Clavigero, que na sua Historia já escrevera: "Mas a função mais importante do sacerdócio, e a principal cerimônia da religião dos mexicanos consistia nos sacrifícios que faziam ocasionalmente para obter algum favor dos céus, ou em gratidão pelos favores já recebidos”(3).

Para falar dos pormenores da morte ritual entre esse povo, temos, em primeiro lugar, os relatos esparsos pela literatura cronística dos primeiros tempos da conquista. Outras

(1) "Por ocasião dos primeiros prodígios, o senado decretara que os cônsules oferecessem as grandes vítimas àqueles deuses que julgassem adequado apaziguar.”

(2) ROBELO, Cecilio A. Diccionario de mitología Nahoa. In: Anales del museo nacional de México, n. 5, 1908. p. 152.

(3) CLAVIGERO, F. S. The history of Mexico. Trad. de Charles Cullen. v. I, VI, p. 50. 
fontes, como os códices pictóricos e as revelações de ciências como a etnologia e a arqueologia, embora tenham reconhecido valor informativo, não serão levados em conta neste trabalho. Sobretudo as crônicas do século XVI contêm uma fonte de informação específica, que são os relatos de observadores presenciais e as notícias colhidas junto a testemunhas dos acontecimentos.

Uma primeira observação a fazer é que, na cultura onde os cronistas foram formados, em parte pelos vínculos ainda notáveis que ela mantinha com a experiência clássica grega e romana ${ }^{(4)}$, a prática do sacrifício, na sua forma mais extrema, conquanto pudesse ser compreendido em toda a sua dimensão religiosa e humana, era terminantemente vedada por mandamentos sociais declarados em preceitos jurídicos, religiosos e culturais. Tendo em vista esse estado de coisas, a mentalidade que presidia o culto sacrificial tal como este existia entre os mexicanos era negada pela parte europeia como sendo algo absolutamente incompatível com o seu modo de ser. Não importa se entre os recém-chegados se achassem religiosos de ordens, treinados para observar a tolerância no trato com estranhos vivendo sob outros costumes, ou civis e militares, por vezes, até alheios aos apelos da religião. A realidade é que todos, indistintamente, viam o sacrifício como um obstáculo intransponível para a coexistência como o requer a vida em sociedade. Para resumir o assunto, basta dizer que o espetáculo da morte ritual encenado pelos aborígenes mostrou aos europeus que o novo começo que pretendiam dar à América obrigaria a uma proibição dessa prática. Essa virada no estatuto da morte ritual no continente constitui, por si mesmo, um fato relevante para quem pretenda ter uma visão mais apurada do que contou e talvez ainda conte na história do continente.

Nos trechos da literatura cronística que apresentaremos em seguida, o ponto de vista do cronista será, obviamente, o nosso guia enquanto procuramos ao menos captar a dimensão que atingiu o sacrifício entre os astecas.

(4) Existem poucas dúvidas de que o sacrifício humano jamais existiu entre os romanos, ao menos de forma sistemática. Alguns registros feitos por seus historiadores dão testemunho tão só de ocorrências isoladas, como vemos em Lívio, que fala de "sacrifícios extraordinários" para apaziguar os deuses, conquanto "ante hostiis humanis, minime romano sacro” ("em relação a vítimas humanas, o sacrifício é o que há de menos romano”) (XXII,57,6). G. Wissowa, por sua vez, ao comentar as influências estrangeiras exercidas sobre a religião romana, mostra que "a inovação mais importante (introduzida em Roma por cultos de origem itálica e grega) nas diretrizes (do culto romano) foi que, em casos difíceis de necessidade pública, os livros sibilinos lançavam mão também de disposições sobre o sacrifício humano, coisa que o antigo código cerimonial romano não conhecia” (grifo nosso). O mesmo autor observa que, apesar do esforço de alguns mitólogos para encontrar em determinados usos do culto romano alternativas simbólicas de sacrifícios humanos, "a realidade é que nos antigos cultos aos deuses nada aponta para essa prática, e assim as evidências são de que a visão religiosa romana descartava o sacrifício humano, bastando para tanto chamar a atenção para o diverso tratamento dado aos homens e aos animais por ocasião do Ver sacrum (sagração da primavera): enquanto os últimos eram sacrificados, os primeiros eram corridos como sacri para o estrangeiro e deixados à mercê da divindade”. (WISSOWA, 1902, p. 354) O certo é pois que os romanos praticavam regularmente sacrifícios de animais, e dentre estes os dos domésticos apenas. Em seu trabalho sobre a experiência religiosa entre esse povo, Fowler comenta: "Para meu propósito atual, qual seja a elucidação do significado que os romanos atribuíram ao culto sacrificial, será suficiente assinalar que todas as vítimas, pelo que sabemos, eram animais domésticos, e em quase todos os casos constituíam uma propriedade valiosa (pecunia), pertencente ao rebanho do proprietário latino, como o boi, a ovelha, o porco, variando em idade e sexo. Bodes [e cabras] foram usados nas Lupercalia, e um cavalo era sacrificado a Marte... e nas Robigalia, em abril, um cão vermelho era oferecido ao espírito do míldio.” (FOWLER, W. Warde. The religious experience of the roman people from the earliest times to the age of Augustus, p. 179). O fato de o sacrifício limitar-se a animais domesticados tem o seu significado, qual seja, o de esse tipo de animal já estar, de certo modo, destinado à morte, para fim alimentar ou para servir o homem na sua casa. 


\section{Juan Díaz, Cortés e o Anônimo}

Juan Díaz, o suposto autor do Itinerario de la Armada, capelão na expedição à ilha de Yucatán, comandada por Juan de Grijalva, em 1518, deixou este testemunho ${ }^{(5)}$ : "Y llegados cerca de los montes, nos encontramos en el principio o cabo de una isleta que estaba en medio de aquellos montes, distante de ellos unas tres millas; surgimos y saltamos todos en tierra en esta isleta, que llamamos Isla de los Sacrificios: es isla pequeña y tendrá unas seis millas de bojeo; hallamos algunos edificios de cal y arena, muy grandes, y un trozo de edificio asimismo de aquella materia, conforme a la fábrica de un arco antiguo que está en Mérida, y otros edificios con cimientos de la altura de dos hombres, de diez pies de ancho y muy largos; y otro edificio de hechura de torre, redondo, de quince pasos de ancho, y encima un mármol como los de Castilla, sobre el cual estaba un animal a manera de león, hecho asimismo de mármol, y tenía un agujero en la cabeza en que ponían los perfumes; y el dicho león tenía la lengua fuera de la boca, y cerca de él estaba un vaso de piedra con sangre, que tendría ocho días, y aquí estaban dos postes de altura de un hombre, y entre ellos había algunas ropas labradas de seda a la morisca, de las que llaman almaizares; y al otro lado estaba un ídolo con una pluma en la cabeza, con el rostro vuelto a la piedra arriba dicha, y detrás de este ídolo había un monton de piedras grandes; y entre estos postes, cerca del ídolo, estaban muertos dos Indios de poca edad envueltos en una manta pintada; y tras de las ropas estaban otros dos Indios muertos, que parecía haber tres días que lo fueron, y los otros dos de antes llevaban al parecer veinte días de muertos. Cerca de estos Indios muertos y del ídolo había muchas cabezas y huesos de muerto, y había también muchos haces de pino, y algunas piedras anchas sobre las que mataban a los dichos Indios. Y había allí también un árbol de higuera y otro que llaman zuara, que da fruto. Visto todo por el capitán y la gente, quiso ser informado si esto se hacía por sacrificio, y mandó a las naves por un Indio que era de esta provincia, el que viniendo para donde estaba el capitán, cayó de repente desmayado en el camino, pensando que lo traían a quitarle la vida. Llegado a la dicha torre le preguntó el capitán, porqué se hacia tal cosa en esa torre, y el Indio le respondió que se hacía por modo de sacrificio; y según lo que se entendió degollaban a estos en aquella piedra ancha y echaban la sangre en la pila, y les sacaban el corazón por el pecho, y lo quemaban y ofrecían a aquel ídolo; les cortaban los molledos de los brazos y de las piernas y se los comían; y esto hacían con sus enemigos con quienes tenían guerra”(6). $\mathrm{O}$ Itinerario gozou de grande voga em sua época, tendo alcançado cinco edições impressas entre 1520 e 1522. Em outra passagem, na qual, como na anterior, já despontam os vocábulos ameríndios, Díaz conta o seguinte: "Aquí cerca de un río vimos que una canoa o barca de Indios había pasado de la otra banda, y traían un muchacho y le sacaban el corazón y lo degollaban ante el ídolo; y pasando de la otra banda el batel de la nao capitana, vieron una sepultura en la arena, y cavando hallaron un muchacho y una muchacha que parecían muertos de poco tiempo; tenían los dichos muertos al cuello unas cadenillas que podían pesar unos cien castellanos, con sus pinjantes; y los dichos muertos estaban envueltos en ciertas mantas de algodón. Cuatro de nuestros esclavos salieron del real y fueron al dicho

(5) Em geral, damos o texto na versão original em espanhol, tal como se acha em cada edição utilizada, ainda que isto ocasione conflito com a ortografia atual do espanhol.

(6) Itinerario de la armada del rey católico a la Isla de Yucatán. 
pueblo de los Indios, quienes les recibieron muy bien, les dieron de comer gallinas, los aposentaron y les enseñaron ciertas cargas de mantas y mucho oro, y les dijeron por señas que habían aparejado las dichas cosas para traerlas a otro día al capitán”(7).

Fernando (assim se lê na sua correspondência) Cortés deixou registrado numa de suas Cartas de Relación (publicadas em 1523) a seguinte impressão sobre o sacrifício no México: "Y tienen otra cosa horrible y abominable y digna de ser punida que hasta hoy no habíamos visto en ninguna parte, y es que todas las veces que alguna cosa quieren pedir a sus ídolos para que más acepten su petición, toman muchas niñas y niños y aun hombre y mujeres de mayor edad, y en presencia de aquellos ídolos los abren vivos por los pechos y les sacan el corazón y las entrañas, y queman las dichas entrañas y corazones delante de los ídolos, y ofreciéndolos en sacrificio aquel humo. Esto habemos visto algunos de nosotros, y los que lo han visto dicen que es la más cruda y espantosa cosa de ver que jamás han visto”(8). A informação transmitida por Cortés, embora pouco precisa sobre os pormenores do sacrifício, comparada com o de outros cronistas da primeira hora, seria lida na principal corte europeia da época.

Entre as primeiras testemunhas do culto sacrificial está também o Conquistador Anônimo, o qual diz: "Eles sempre celebram os festivais de seus ídolos sacrificando muitos homens e mulheres, rapazes e moças, e quando sentem a necessidade de algo imprescindível como a chuva, ou o excesso de chuva, ou quando veem perigo em seus inimigos, ou sofrem alguma outra calamidade, fazem esses sacrifícios da seguinte maneira: (segue-se uma gravura com a cena do martírio)”(9). O companheiro de Cortés descreve o sacrifício com algum pormenor: "Tomam aquele que será sacrificado, levam-no pelas ruas e praças, ricamente vestido, com grande festa e exultantes. Muitos contam-lhes suas necessidades, dizendo que como ele vai aonde está seu Deus, pode dizer-lhe algo para ajudá-los. Então lhe dão refrescos e outras coisas. Desse modo, ele recebe muitos presentes, o que ocorre quando alguém que matou um lobo carrega a cabeça pelas ruas. E todos os presentes vão para aqueles que oferecem os sacrifícios. Levam-no ao templo, onde dançam e continuam com alegria, e o homem que vai ser sacrificado dança e continua como os outros. Depois de algum tempo o homem que oferece o sacrifício o desnuda e o leva imediatamente à escadaria da torre onde está a ídolo de pedra. Ali o deitam de costas, atam-lhe as mãos nos flancos e amarram as pernas. Então todos começam a cantar e a dançar a sua volta, cantando a mensagem principal que diz que ele deve ser entregue ao deus. Logo vem o sacerdote sacrificador - e esta não é uma função pequena entre eles — armado com uma faca de pedra, que corta como aço, e tão grande quanto as nossas facas grandes. Crava a faca no peito, abrindo-o, e arranca o coração quente e palpitante. E isto com a mesma rapidez com que se faz o sinal da cruz. Neste momento o sacerdote chefe do templo toma-o e besunta a boca do ídolo principal com o sangue; daí, estende a mão cheia de sangue na direção do sol, ou de alguma estrela, se for noite. Então, besunta as bocas de todos os outros ídolos de madeira e de pedra e borrifa com sangue a cornija da capela do ídolo principal. Em seguida, queimam o coração, preservando as cinzas como grande relíquia, e do mesmo modo queimam
(7) Idem.
(8) Cartas de relación, p. 26.
(9) $O$ anônimo conquistador, p. 50. 
o corpo do sacrificado, mas estas cinzas são guardadas à parte num outro vaso"(10). Observações feitas na província de Panuco levam o Anônimo a estabelecer uma correlação entre o martírio e a paixão religiosa. Ele ficou impressionado com as combinações bizarras de culto, fetichismo e conduta extravagante. "Aquelas pessoas, diz, de todas que Deus criou, são as mais devotas e seguidoras de sua religião, a ponto de se oferecerem em sacrifício voluntário para a salvação de suas almas. Tiram sangue da língua, das orelhas, das pernas e dos braços para oferecê-lo em sacrifício a seus ídolos. Existem nas redondezas e ao longo das estradas muitas ermidas ou oratórios, onde os viajantes vão derramar seu sangue e oferecê-lo a seus ídolos. Até nos cumes das montanhas mais altas existiram oratórios tidos numa veneração especial”(11).

\section{Bernal Díaz Del Castillo}

Chegado à América em 1514, como simples soldado de obscura prosápia, Bernal Díaz del Castillo participou em várias expedições militares, inclusive na mais célebre de todas, iniciada em 1518, sob o comando de Cortés, dirigida à conquista do México. Tendo-se destacado em armas, buscou refúgio para a vida madura na Guatemala, onde se estabeleceu com uma encomienda, até que a publicação por Gómara da Crónica de la Conquista de la Nueva España, em 1552, tirou-o de seus afazeres, levando-o a escrever a sua própria versão dos mesmos fatos, na qual procurava corrigir o que lhe parecera o indevido destaque dado pelo cronista a Cortés. O livro de Bernal Díaz é inestimável para o conhecimento das jornadas mexicanas da conquista e como leitura sobre aqueles tempos. Nas passagens em que fala do sacrifício os pormenores são mais nítidos do que nos relatos citados, como nesta em que um comandante e seus subordinados dão o seu testemunho: "Llegado Pedro de Alvarado a los pueblos, todos estaban despoblados de aquel mismo día, y halló sacrificados en unos cúes hombres y muchachos, y las paredes y altares de sus ídolos con sangre, y los corazones presentados a los ídolos; también hallaron las piedras sobre las que sacrificaban, y los cuchillos de pedernal con que los abrían por los pechos para sacarles los corazones. Dijo Pedro de Alvarado que habían hallado todos los más de aquellos cuerpos muertos sin brazos y piernas, y que dijeron otros indios que los habían llevado para comer. Nuestros soldados se admiraron mucho de tantas crueldades. Dejemos de hablar de tanto sacrificio, pues de allí adelante en cada pueblo no hallábamos otra cosa, y volvamos a Pedro de Alvarado" ${ }^{(12)}$. Neste trecho os indígenas aparecem desafiando Cortés: "Llegados a nuestro real sahumaron a Cortés, y sin hacer acato, como suelen entre ellos, dijeron: 'Esto os envía el capitán Xicotenga que comáis. Si sois teúles bravos, como dicen los de Cempoal, y queréis sacrificios, tomad esas cuatro mujeres que sacrifiquéis, y podéis comer de sus carnes y corazones; y porque no sabemos de qué manera lo hacéis, por eso no las hemos sacrificado ahora delante de vosotros. Y si sois hombres, comed de estas gallinas, pan y fruta; y si sois teúles mansos, aquí os traemos copal (que ya he dicho que es como incienso) y plumas de papagayos. Haced vuestro sacrificio con ello. Cortés respondió con nuestras lenguas, que

(10) Ibidem, p. 51-53.

(11) Ibidem, p. 54.

(12) CASTILLO, Bernal Díaz del. Verdadera historia de los sucesos de la conquista de la nueva España, p. 38. 
ya les había enviado a decir que quieren paz y que no venía a dar guerra, y les venian a rogar y manifestar de parte de Nuestro Señor Jesucristo, que es Él en quien creemos y adoramos, y el emperador don Carlos (cuyos vasallos somos), que no maten ni sacrifiquen a ninguna persona, como lo suelen hacer; y que todos nosotros somos hombres de hueso y de carne como ellos, y no teúles, sino cristianos, y que no tenemos costumbre de matar a ningunos"(13).

Uma vez na cidade dos mexicanos, Montezuma e Cortés visitam o grande templo onde os sacrifícios têm a sua apoteose: "Y cuando llegamos cerca del gran cu, antes que subiésemos ninguna grada dél, envió el gran Montezuma desde arriba, donde estaba haciendo sacrificios, seis papas y dos principales para que acompañasen a nuestro capitan Cortés, y al subir de las gradas, que eran ciento y catorce, le iban a tomar de los brazos para le ayudar a subir, creyendo que se cansaria, como ayudaban a subir a su señor Montezuma, y Cortés no quiso que llegasen a él; y como subimos a lo alto del gran cu, en una placeta que arriba se hacia, adonde tenian un espacio como andamios, y en ellos puestas unas grandes piedras adonde ponian los tristes indios para sacrificar, allí habia un gran bulto como de dragon e outras malas figuras, y mucha sangre derramada de aquel dia. E así como llegamos, salió el gran Montezuma de um adoratorio donde estaban sus malditos ídolos, que era en lo alto del cu, y vinieron con él dos papas, e con mucho acato que hicieron a Cortés e a todos nosostros le dijo: 'Cansado estaréis, señor Malinche, de subir a este nuestro gran templo’. (...) E otro ídolo pequeño que allí cabe él estaba, que decian era su paje, le tenia una lanza no larga y una rodela muy rica de oro e pedrería, e tenia puestos al cuello el Huichilóbos unas caras de indios y otros como corazones de los mismos indios, y estos de oro y dellos de plata con mucha pedrería azules; y estaban allí unos braseros con incienso, que es su copal, y con tres corazones de indios de aquel dia sacrificados, e se quemaban, y con el humo y copal le habian hecho aquel sacrificio; y estaban todas las paredes de aquel adoratorio tan bañadas y negras de costras de sangre, y asimismo el suelo, que todo hedia muy malamente. (...) E en aquella placeta tenian tantas cosas muy diabólicas de ver, de bocinas y trompetillas y navajones, y muchos corazones de indios que habian quemado, con que rahumaban aquellos sus ídolos, y todo cuajado de sangre, y tenian tanto, que los doy a la maldición; y como todo hedia a carnicería, no viamos la hora de quitarnos de tan mal hedor y peor vista"(14).

Quando a guerra com os mexicanos se intensificou, uma arma destes foi ameaçar com a expectativa do sacrifício: "Pues lo que decian, que en aquel dia no habia de quedar ninguno de nosostros, y que habian de sacrificar a sus dioses nuestros corazones y sangre, y con las piernas y brazos, que bien tendrian para hacer hartazgas y fiestas; y que los cuerpos echarian a los tigres y leones y víboras y culebras que tienen encerrados, que se harten dellos; e que a aquel efecto há dos dias que mandaron que no les diesen de comer; y que el oro que teniamos, que habriamos mal gozo dél y de todas las mantas; y a los de Tlascala que con nosostros estaban les decian que les meterian en jaulas a engordar, y que poco a poco harian sus sacrificios con sus cuerpos”(15).

(13) Ibidem, p. 63.

(14) Ibidem, p. 89 ss.

(15) Ibidem, p. 131. 


\section{DURÁN}

Diego Durán conta como o general e irmão de Montezuma I (1398-1469), Tlacaélel, maquinou o aperfeiçoamento do sistema de sacrifícios, especialmente após a vitória sobre os guastecas, quando uma nova pedra foi arranjada para servir ao ritual: "Despues de pasados muchos dias que auian venido de la guerra de la Guasteca los mexicanos, Tlacaelel acordó al rey Monteçuma la obra que del templo auia empeçado á hacer, trayéndole á la memoria cómo era menester labrar una piedra ancha que siruiese como de altar ó mesa donde se celebrasen y se matasen los que auian de ser sacrificados, porque este Tlacaelel, demás de ser valeroso y muy auisado en auisos y ardides de guerra, fué inventor endemoniado de sacrificios crueles y espantosos; y así dándole orden el rey Monteçuma para que mandase hacer la piedra, mandóle también que pusiese en ella y mandase esculpir la guerra que tuvieron los antepasados con los azcaputzalcos, quando se libertaron, para que estuviese allí en perpetua memoria esculpida. Tlacaelel se olgó dello y mandó llamar á todos los canteros y entalladores y díxoles: Maestros, el nuestro señor manda que se haga una piedra grande y redonda la qual se a de llamar Temalacatl, que quiere decir rueda de piedra, en la haz de la qual an de estar pintadas las guerras que tuvimos con los tepanecas, la qual escultura quiere que sea perpetua memoria de aquella admirable açaña; y ruegoos que celebréis vuestros nombres y ençalceis vuestro nombre y eterna memoria en que vaya muy bien labrada y con toda la breuedad posible. Los maestros dixeron que les placía de lo hacer; y buscando una gran piedra, que tenia de ancho braça y media, la allanaron, y en ella pintaron la guerra de Azcaputzalco, muy bien esculpida, y acauáronla en tan breue que no tardaron muchos dias quando dieron auiso al rey de que la mesa del sacrificio estaua acauada, el qual mandó que se le hiciese un poyo alto donde se pusiese, y así se hiço un poyo alto y encima del la mandaron poner, que señorease un gran estado de hombre”.

"Puesta la piedra en su lugar, llamaron á algunos manceuos de los que estauan recogidos en los templos, de los mas principales, y dieron el oficio de exercitar el sacrificio quel demonio les auia inventado y enseñado, y dixéronles: mira que todos estos dias os ensayéis para exercitar este sacrificio, porque an de ser convidados á esta fiesta todos los señores de las ciudades y prouincias comarcanas y es menester que no nos echéis en vergüenza. Los manceuos les dieron las gracias y prometieron de se exercitar y ensayar, y así empeçaron á se ensayar conforme á la instrucion que los dieron, y ya que se acercaua el dia de las fiestas y principio de su mes, que se llamaua Tlacaxipehualizili, que quiere decir desollamiento de hombres, enviaron á convidar á los señores de toda la redonda; al rey de Tezcuco y al de Tacuba, á los de Chalco y Xuchimilco, á todos los del marquesado y á los de Conixco y Matlatzincoy los Maçahuaques; finalmente, convidaron toda la mas gente que pudieron de la redonda, para que viniesen á ver lo que aquella fiesta significaua y lo que en ella se hacia” ${ }^{(16)}$.

A pedra referida possivelmente é a de Tizoc, descoberta em 1791, a qual possui as características descritas por Durán. Este autor é talvez a melhor fonte sobre Tlacaélel, un personagem central na consolidação do regime asteca. Por meio dos fatos narrados por

(16) Durán, Historia de las Indias de Nueva España y Islas de Tierra Firme, I, XX, p. 174-175. 
Durán, pode-se ter uma ideia das reformas levadas a cabo por este general, verdadeiro arquiteto do império asteca, que elevou os sacrifícios a ritual perpétuo, periódico e ostensivo, institucionalizando-os num novo patamar de grandeza. Também promoveu a elevação de Huitzilopochtli (em náhuatl, o beija-flor do Sul), deus solar da guerra, à posição suprema no panteão divino, deu regularidade à "guerra florida" (xochiyaoyotl) contra os povos circunvizinhos, na qual se tomava o cuidado de preservar a vida de cativos depois encaminhados ao martírio ${ }^{(17)}$, e, mediante a proibição do uso de certos adereços pelas camadas inferiores, criou os símbolos de distinção dos membros da nobreza política e militar. A importante reorganização do sacrifício em torno da Temalacatl tomou proporções cívicas através dos arranjos feitos para convertê-la no centro da grande festa destinada a celebrar o poderio mexicano de relativa antiguidade, como conta Durán: "Llegados que fueron, luego mandó el rey sacar de sus tesorerías gran cantidad de mantas muy galanas y bragueros y vestir á todos los señores de muy vistosa ropa de muchas labores y plumería, y muy galanos y anchos ciñidores y cotaras y beçotes de ricas piedras y orejeras de oro y nariceras: luego empeçaron á sacar muchas y muy buenas comidas de aues y diversas carnes de montería, muchas diferencias de pan, de beuidas de cacao y vino á su usança. Después que uvieron comido y bebido, pusiéronse á unos miradores que les tenían hechos y aderezados de muchas rosas y juncia, y estando allí esperando lo que se auia de celebrar, no auiendo visto cosa semejante, sacaron los presos todos y pusiéronlos en renglera en un lugar que llamauan Tzunpantitlan, que quiere decir casi lo que quiere decir monte caluario, ó lugar de calauernas, que eran unas gradas largas donde auia una paliçada, donde ensartaban las calauernas de los sacrificados, donde perpetuamente estauan por memoria y reliquias para eternal memoria. Allí pusieron en renglera estos presos y mandáronles que bailasen, y así estauan todos bailando: estos presos estauan todos embijados con yeso y las caueças emplumadas y en medio de la coronilla unas plumas atadas al cauello, blancas, tiznado todo el beço de los párpados y al rededor de los labios de colorado"(18).

Em seguida vem a execução do chamado sacrifício gladiatório: "Puestos allí, salieron luego los sacrificadores y puestos en su orden, conforme á la dignidad de su oficio; es de sauer que todos venían vestidos en áuito de los dioses: uno venia vestido con el traje de ydolo Vitzilopochtli, el otro en el áuito de Quetzalcoatl, otro en el de Toci, otro en el áuito de Yopi, otro en el de Opochtzin, otro en el áuito de Totec, y otro en el áuito de Itzpapalotl: otro venia en el áuito de tigre, otro en áuito de león, otro en áuito de águila. Todos estos traían en las manos sus espadas y rodelas, todas guarnecidas de oro y de joyas, y ellos cargados de plumas y de joyeles y de mucha riqueça, á los quales tenían hecha una ramada muy galana de muchas rosas y pinturas que significauan las insignias de todos aquellos dioses. Esta ramada era de una rama y oja de un árbol que llaman tzapotl, y así llaman á esta ramada Çapotlcalli; tenían de dentro unos asientos del mesmo palo del çapotl donde se asentaron todos por sus antigüedades. Estaua esta ramada en lo alto del templo, en un lugar que llamauan Yopico. Asentados estos que representauan la semejança de los dioses y eran los que auian de hacer el sacrificio, salieron luego los viejos que llamamos Tecuacuiltin y los cantores del templo y pusieron su atambor y al son del empeçaron á bailar y cantar.

(17) Vide, de DUVERGER, Christian. La flor letal economía del sacrificio Azteca, p. 204-205.

(18) DURÁN. Op. cit., p. 176. 
Salió el principal y sumo sacerdote, muy bien vestido de pontifical, con sus plumas altas en la tiara y sus vestiduras pontificales, llenos los braços de brazeletes de oro, de los quales salían grandes y resplandecientes plumas verdes y açules, y en la mano un cuchillo ancho de nauaja negra, al qual cuchillo llamaua yxquauac, y sentáuase en un lugar que en particular le tenian adereçado. Sentado allí, traian uno de los presos que de la Guasteca auian traido, y en una soga que del medio de la piedra salia por un aguxero que en medio tenia, atáuanle allí un pié, por la garganta, y en atándole dáuanle en la mano una espada de palo y una rodela, y la espada no tenia nauajas sino toda emplumada de arriba abajo. Leuantáuase luego el sumo sacerdote, que para este dia le llamauan Youalaua y Totec, y descendía poco á poco por las gradas hasta donde el preso estaua y daua dos vueltas al rededor de la piedra y bendecíala, y al que en ella estaua atáualo y voluíase á su asiento. Luego venia uno de los viejos que andaua en áuito de león y traia al que estaua atado en la piedra quatro pelotas, hechas de palo de tea, y dáuaselas, ó poníaselas junto á él, y decíale que se defendiese y atáuales un paño por el cuerpo y dáuale á beber un poco del vino de los dioses y con esto se iba y lo dexaua allí”.

"Luego salia uno de aquellos que representaban los dioses y veníase acia la piedra, bailando con su rodela y espada en la mano, armado con sus coracinas íbase para el que estaua atado: el miserable yndio tirábale las pelotas que allí tenia, las quales, si el sacrificador ó verdugo era diestro rebatíalas, y luego el preso tomaba su espada emplumada y defendíase lo que podia, y algunos auia tan diestros que cansauan dos ó tres antes que los pudiesen herir otros: el primero (combatente) los heria en una pierna ó en el cuerpo ó en los braços; de suerte, que en hiriéndole, en qualquier parte que fuese, salian quatro leuitas, todos embijados de negro, los cauellos largos y trançados, vestidas unas como casullas y subían á la piedra y echaban al herido boca arriba y asíanle de los pies y de las manos y leuantáuase el sumo sacerdote y abríalo por el pecho con aquel cuchillo, y sacáuale el coraçon y ofrecia al sol el vaho que del salia. Ya que se enfriaua, dáualo á aquellos ministros, los quales lo ponian en un lugar que llamauan Cuauhxicalli, que era otra piedra grande que era dedicada al sol y tenia en medio una pileta donde se hacian otros sacrificios diferentes deste”(19).

O ritual como um todo trazia uma mensagem aos espectadores forasteiros, como ressalta Durán: "Después de muertos todos los que se auian de sacrificar, tuviéronlos todos aquellos cuerpos al mesmo lugar donde auian estado en renglera y echávanlos allí, y los que auian exercitado este sacrificio entráuanse en los lugares del templo con el sumo sacerdote y desnudáuanse de aquellas vestiduras y poníanlas con mucha reverencia en lugares decentes. Los señores de las prouincias y ciudades, admirados y asombrados de semejante sacrificio, partiéronse para sus prouincias y pueblos llenos de temor y espanto"(20).

Os que atuavam no sacrifício eram homenageados pelo imperador: "Luego Monteçuma mandó llamar á los que auian sacrificado (os sacrificadores) y mandólos vestir de mantas y ceñidores y cotaras, y híçoles grandes mercedes por lo bien que lo auian hecho: mandóles dar maiz, frisoles, chia, cacao, todo en cantidad, todo para animar á otros á estos exercicios que á ellos les parecía eran de virtud y de honra. Otro dia, que fué el de la torna boda

(19) Ibidem, p. 176-178.

(20) Ibidem, p. 178. 
(refere-se à festa do dia seguinte), lo qual es Rito antigo el tener las fiestas torna boda; vestia el rey á todos los señores de mantas muy galanas y de zeñidores muy galanos y de cotaras y de becotes, orejeras: dáuales rodelas, armas y deuisas muy vistosas y galanas y de precio, con sus banderetas de oro; finalmente, á todos, según su dignidad, daua las deuisas y ynsignias que merecían, á unos mejores y á otros no tales, y así ninguno quedaua que no hiciese mercedes en semejantes fiestas y solenidades, pero era á todas las personas señaladas y aunque no lo fuese, que uviese hecho alguna cosa notable en la guerra”(21).

As cerimônias se encerravam com o esfolamento das vítimas e o recobrimento do corpo de esmoleres com o couro arrancado, como se lê adiante: "Vestidos todos y hechas las solenidades referidas, desollauan todos aquellos indios sacrificados y vestíanse aquellos cueros otros indios, á los quales llamauan Tototectin: dáuanles sus rodelas en las manos y en la otra unos báculos con unas sonajas en ellos, y andauan de casa en casa, primero todas las casas de los señores y de los mandoncillos, y luego por todas las demás casas, á pedir limosna con aquellos cueros vestidos: dáuanles los señores mantas, bragueros y ceñidores, la demás gente común dauan manojos de maçorcas y otras cosas de comer: andauan veinte dias estos limosneros y recogian gran cantidad de mantas y de cosas de comer: andauan vestidos sobre aquellos cueros, á la manera que el dios de aquella fiesta estaua. Pasados los veinte dias dexauan aquellos cueros hediondos y enterráuanlos en una pieza del templo que auia para solo aquel effeto, y así se concluya la fiesta y se concluyó el sacrificio que de los guastecas se hiço á honra de la solenidad del estreno de la pieça, y así concluye el capítulo que en la lengua mexicana hallé escrito"(22).

Pelo que nos diz Durán, o sacrifício, sob Montezuma I e Tlacaélel, adquire um fim nitidamente político de atemorizar os possíveis adversários: "Esta es la solenidad que Monteçuma el viejo, primero de este nombre, hiço al estreno de la piedra llamada Temalacatl, que quiere decir rueda de piedra, para la qual mandó llamar todos los señores de todas las prouincias, y mató en ella todos los tochpanecas y todos los que de la guerra guasteca truxeron presos, á honra de la qual fiesta hiço un gasto exceçivo y muy costoso con mucha liberalidad y generosidad, que dexó espantados á los forasteros y muy contentos y ufanos á todos los señores y populares de la ciudad. Desde entonces todos los de las prouincias y ciudades comarcanas dexaron de tratar reueliones ni contiendas con los mexicanos, viendo quán adelante estauan y cómo tratauan á sus enemigos”(23).

O sacrifício por esfolamento também era executado durante uma festa especial, chamada de Tlacaxipeualiztli. Na sua descrição, Durán dá conta também do sacrifício gladiatório, terminando no esfolamento da vítima: "En la ystoria que hice de los sacrificios (está na $2^{a}$ parte) conté muy á la larga de la fiesta de Tlacaxipeualiztli, que quiere decir desollamiento de hombres, y el modo que en celebralla tenían, que era atar á los presos con una soga al pié, por un agujero que aquella piedra por medio tenia, y desnudo en cueros le dauan una rodela y una espada, de solo palo emplumada, en las manos y unas pelotas de palo con que se defendía de los que salían á combatir con él, que eran quatro muy bien 
armados, á los quales llamauan tlauauanque, que quiere decir, curtidores ó raedores de cueros, de los quales algunos se defendían por alargar un poco mas la vida, otros por concluir luego se dexauan matar luego, dándoles encima de aquella piedra las heridas, y luego pasándolos á la piedra del sol, allí los acababan de sacrificar con todas las cerimonias que allí referî”(24).

As intervenções de Tlacaélel nestas festas mostram, mais uma vez, o seu empenho em utilizar o sacrifício para subjugar as tribos vizinhas: "Acauada, pues, la guerra de los matlatzincas, y traydos mucha moltitud dellos presos á México, llegóse esta fiesta de los desollados, y hablando Tlacaelel al rey le dixo: hijo mio, ya ves mis canas y vejez; suplicóte no aguardes á mas tarde á poner las mesas y piedras del sacrificio, pues saues se llega la fiesta del desollamiento de hombres, porque si la dilatas morirme e mañana ó esotro dia, y no llevaré este contento de auer goçado della; lo qual hacia el maluado viejo porque no se veya harto de carne humana. El rey le respondió, que le placía de luego las mandar poner; y así fué que, convocadas todas las prouincias, se juntó en México gran número de gentes, como para mover semejantes piedras convenia, las quales fueron puestas en lo alto del templo. Después de puestas y perficionado todo lo mas curiosamente quellos supieron, dixo Tlacaelel al rey: ya está hecho lo mas; lo que falta es que envies á convidar huéspedes para que se hallen á la solenidad y fiesta. El rey le respondió, que á qué gente le parecía que convidase, que fuese dina deste sacrificio y fiesta. Él le respondió, que deuia de convidar á los nonoualcas, cempualtecas y quiauiztecas, dos prouincias que residen junto á la costa, las quales hasta entonces no se auian conquistado; y á esta causa dixo el viejo Tlacaelel, la causa de advertirte que convides á estos, es para ver si nos obedecen y vienen á nuestro llamado, porque si no, ternemos ocasión para mouelles guerra y para destruillos, y esta es mi intinción; los quales, si vinieren, entenderemos están á nuestro seruicio y hacelles emos honra”(25).

Durán descreve também o sacríficio regular duma índia à deusa Cihuacoatl, a principal do sexo feminino, adorada pelos xochimillcas do México e de Tezcoco, assim retratada: "de piedra, tenia vna boca muy grande abierta y los dientes regañados tenia en la caueça una cauellera grande y larga y vn abito de muger todo blanco de naguas y camissa y manto". Em sua festa, chamada de Hucitecuilhuitl, festa grande ou dos senhores, por estes celebrada, "lo primero que hacían era que beinte dias antes desta fiesta comprauan vna esclaua y purificauanla y luego bestianla a la mesma manera questaua uestida la de piedra de blanco toda con su manto blanco la qual assi bestida repressentaua a la diossa haçiéndole la honra y buen tratamiento que a ella mesma hicieran si biba se les representara traiendola de boda en boda y de banquete en banquete y lleuandola a todos los mercados representandole todos los géneros de contento y regocijo que podian. Trayanla siempre embriagada fuera de su natural juicio vnos dicen que con bino, otros que demas de dalle bino le dauan no se que hechiços juntamente para que andando sienpre alegre no se acordase que hauia de morir. De noche dormia en vna jaula por temor de que no se les huyese. Llamauan a esta yndia Xilonem. Desde el dia que la purificauan hasta que la matauan que era el mesmo dia de la fiesta vna ora antes que amaneciese matando primero quatro presos y hechandolos

(24) Ibidem, XXXVI, p. 280-281.

(25) Ibidem, p. 281. 
tendidos en el suelo pegados muy juntos vnos con otros echauan esta yndia encima dellos y degollauanla coxiendo la sangre en un lebillejo y después sacándole el coraçon dauan con el a la diossa de piedra y ruciandola con la sangre de la yndia ruciauan juntamente toda la sala y todos los ydolillos, y los cuerpos dauan a sus dueños para celebrar la comida todo esto se haçia de mañana vna ora antes que amaneciesse. Llamauan a aquellos quatro cuerpos de yndios el estrado de pressos de la diossa pero es de saber que a esta diossa hacian el mesmo sacrificio de fuego que a Xocotl según relación de algunos y porque lo alle pintado en vna pintura apropiado a esta diossa y aplicado a ella lo quiero especificar aqui mas a la larga y contar el modo y manera que en lo executar se tenia lo qual era

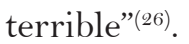

Antes do martírio da índia mencionada, a execução dos quatro índios sacrificados à deusa Cihuacoatl era feita passando-os antes pelo fogo num braseiro que mantinham aceso por quatro dias: "Frontero del brasero diuino sacauan los quatro pressos que le hauian de seruir de estrado y sacrificauanlos delante della desta manera que tomándolos los ministros de aquel tenplo vno a vno dos de las manos y dos de los pies y dando quatro enbiones en el ayre con al quarto enbion dauan con el en aquella gran brassa y antes que acauase de morir sacauanlo de presto y poníanlo assi medio assado en encima de vna piedra y cortauanle el pecho como tengo dicho, y sacauanle el coraçon y echauanselo delante. Lo mesmo hacian del segundo y del tercero y cuarto donde después de sacrificados y puestos en el suelo por estrado matauan a la yndia diossa cojiendole la sangre para haçer la cerimonia dicha y tambien rociauan el fuego con la mesma sangre”(27).

\section{Motolinía}

Motolinía (Toribio de Benavente) conta que na festa do mês panquetzaliztli, dedicada aos deuses irmãos Tezcatlipuca e Vicilobuchtli, os principais do México, eram realizados os sacrifícios de sangue: "En aqueste dia panquetzaliztli, como principal pascua se hacian muchos sacrificios de sangre, ansí de las orejas como de la lengua, que esto era muy comun, otros de brazos y pechos, dándose punzadas de que salia sangre, y de los muslos y de otras diversas partes del cuerpo, y esto era muy comun en toda la tierra, y sacábanla en papeles, y con los dedos rociaban los ídolos, como el que esparce agua bendita; pero de las partes del cuerpo en cada provincia habia su costumbre, uno de los brazos, otros de los pechos, etc., que aun en esto se conocian de qué provincia eran muchos”. A mesa de imolar era um monumento comum e familiar, bem como os apetrechos desse serviço, cuja descrição por Motolínia é bastante precisa: "Desta manera, que tenian una piedra larga de obra de una braza y casi palmo y medio de ancho y un palmo de grueso: lo más de esta piedra ó la mitad estaba hincada en tierra, arriba encima de las gradas delante del altar de los ídolos. En esta tendian de espaldas al desventurado que habian de sacrificar, y el pecho muy teso, teniéndole ó atándole los piés y manos unos de los principales oficiales del demonio, que se llamaban tlamacazque o tlenamacazque, y en esto estaban tan diestros, que de presto con una piedra

(26) Ibidem, t. II, XCI, p. 172-173.

(27) Idem. 
de pedernal de aquellos con que sacan lumbre, hecho como un hierro de lanza, no agudo mucho; porque como es piedra recia y salta, no se puede parar aguda: esto digo porque muchos piensan que eran de aquellas navajas de piedra negra que acá hay que tiene el filo tan delgado como una navaja de barbero y cortan muy dulce, sino que luego se mellan y saltan pedacitos, porque es muy vedriosa la piedra: con aquel cruel cuchillo de pedernal, como el pecho estaba tan teso, y con mucha fuerza abrian al desventurado y de presto sacábanle el corazon, y aquel oficial deste cruel oficio daba con él encima del umbral del altar, de parte de fuera, á do dejaba hecha una mancha de sangre y caía el corazon en tierra, á do estaba un poco bullendo, y delante el altar ponianlo en una escudilla, y á las veces estos corazones los comian los sacerdotes ó alfaquíes viejos: otras veces los enterraban y luego tormaban el cuero y echábanle por las gradas abajo á rodar, y allegado abajo, si era de los presos en la guerra, el que lo prendió, con sus amigos y parientes, llevábanlo y aparejaban aquella carne humana con otras comidas, y otro dia siguiente hacian fiesta, y repartido por aquellos lo comian; y este mismo que hacian la fiesta, si tenia costilla, en aquella fiesta de sua valentía, daba en esta comida mantas: y si era esclavo el sacrificado no le echaban á rodar, sino desde allí lo llevaban á brazos, y hacian la misma fiesta y convite que con el preso de guerra, aunque no tanto. En otras fiestas y dias tomaba el corazon aquel verdugo en la mano y levantábalo hácia el sol y hácia el ídolo, y poníalo delante en una xical de calabaza, que es como una escudilla llana pintada, y en otra cogían la sangre, y daban de ella como de comer al ídolo principal, untándole los bezos, y á los otros ídolos y figuras del demonio: y en estas fiestas sacrificaban destos segun el pueblo: en unos veinte y en otros treinta, y en otros cuarenta, hasta ciento. En las grandes cabeceras de provincias y en México más de ciento"(28).

Motolinía conta do sacrifício por esfolamento de alguns durante a festa de Tlacaxipeualiztli: "En otro dia de aquellos meses, que se llamaba tlacaxipeualiztli, se sacrificaban muchos, no tantos como en la otra fiesta ya dicha, y de aquellos sacrificados desollaban algunos, en unas partes dos ó tres, y en otras cinco ó seis, y en otras diez y en otras más, y en México desollaban hasta doce ó quince, y vestianse aquellos cueros que por las espaldas $\mathrm{y}$ encima de los hombros dejaban abiertos; $\mathrm{y}$ vestidos lo mas justo que podian, como quien viste jubon y calzas, bailaban con aquella cruel y espantosa divisa. Y como todos ó los más sacrificados, eran esclavos ó tomados en la guerra, en México para este dia guardaban alguno de los presos en la guerra, que fuese señor o principal, y aquel desollaban para Moteczuma, el gran señor de México, en el cual cuero bailaba, y esto iban á ver como cosa de maravilla, y en los otros pueblos no se lo vestian los señores, sino otros pincipales. Esta fiesta se llamava de Tlacaxipeualiztli, que tornando en nuestra lengua lo que quiere decir, se dirá "dia de desollamiento de hombre", aunque no de S. Bartolomé"(29).

No dia de Uchpaniztli, a vítima era uma mulher: "Otro dia que se llamba Uchpaniztli sacrificaban una mujer en cada parte y desollábanla, y vestiase el cuero de ella uno, y bailaba con todos los del pueblo dos dias, y los otros, con sus plumajes"(30).

(28) MOTOLINÍA. Memoriales, I, 17, p. 58-59.

(29) Ibidem, p. 60.

(30) Idem. 
No dia de Etzalcoaliztli, dedicado a Tlaluc, deus da água, era a vez de um escravo: "Antes que este dia llegase, veinte ó treinta dias, compraban un esclavo é una esclava, y hacianlos morar juntos como casados, y allegado el dia de Etçalzoaliztli vestian al esclavo con las ropas é insignias del Tlaluc, y á la esclava de las ropas é insignias de su mujer Chalchiuhcueye y bailaban asi todo aquel dia hasta la media noche..."(31).

$\mathrm{Na}$ festa do deus do fogo eram cometidas várias crueldades: "En un otro dia llamado xocotlhuezi, en algunas partes, como Tacuba, Cuyovacan, Azcapuzalco, levantaban un gran palo rollizo de obra de diez brazas, é hacian un ídolo de semillas y envuelto y atado con papeles, y poníanlo encima de aquel palo, y en la vigilia de la fiesta levantaban allá este ídolo en el palo, y el dia todo bailaban á la redonda de él, y el dia de la fiesta por la mañana tomaban algunos esclavos y otros cautivos que tenian de guerra, y traianlos atados de piés y manos, y echábanlos en un gran fuego que para esta crueldad tenian aparejado; y no bien acabado de quemar, sacábanlo del fuego no por piedad que de él habian, mas por darle otros dos tormentos ó muertes, que luego se seguia la segunda, que era sacrificarlos, sacándoles los corazones, y á la tarde echaban el palo en tierra, y trabajaban mucho por haber parte de aquel ídolo, de las semillas que estaba masado con masa de la que en esta tierra hacen pan, por comer algun poquillo, que creian que los hacia valientes hombres”(32).

No dia de Izcalli, cativos de guerra eram sacrificados: "Otro dia que se decia Izcalli, este era dedicado al dios del fuego, á ese mesmo fuego, que lo tenian por dios general por todas partes. En este dia tomaban uno de los cautivos en la guerra, y vestianle de las vestiduras y ropas del dios del fuego, y bailaban en reverencia de aquel dios, y sacrificábanle á él y á los que demas de él tenian presos de guerra; pero mucho más es de espantar de lo que particularmente se hacia aquí en un pueblo que se dice Quauhtitlan, cerca de México, donde esto escribo, adonde mas cruel y soberbio se mostraba el demonio, que en todas las otras partes donde generalmente se hacia”(33).

Tinha lugar em Quauhtitlan, perto do México, na vigília do dia de Izcalli, de quatro em quatro anos, o pior sacrifício: "La vigilia de este dia en Quauhtitlan levantaban seis árboles grandes como mástiles de navio, con sus escaleras, y en esta mesma vigilia cruel, y de mas cruel dia, tambien degollaban dos mujeres esclavas, en lo alto encima de las gradas, ante el altar de los demonios, y allá las desollaban enteramente con sus rostros, y sacábanles las canillas de los muslos; y el dia de la fiesta por la mañana dos indios principales vestianse los cueros con los rostros cubiertos como máscaras, y despues de vestidos tomaban en las manos, en cada una su canilla, y mui paso á paso bajaban bramando por las gradas abajo que pareciam bestias encarnizadas, y estaba abajo en los patios grande muchedumbre de gente, toda como espantada, y decian todos 'ya vienen nuestros dioses, ya vienen nuestros dioses’; y allegados abajo comenzaban á tañer sus atabales; y á los ansí vestidos ponian á cada uno sobre las espaldas mucho papel cosido en ala, casi cuatrocientos pliegos; y una codorniz sacrificada y degollada atábansela á cada uno al brazo que tenia horadado, y de esta manera bailaban estos dos, delante los cuales toda ó la más gente sacrificaban y ofrecian muchas codornices, y echábanselas delante, y eran tantas, que cobrian el suelo por do iban,

(31) Idem.

(32) Ibidem, 19, p. 61.

(33) Idem. 
porque pasaban de ocho mil las que aquel dia ofrecian, porque para esta fiesta las buscaban la gente que á ella venian, de mas de diez y doce leguas, y al medio dia cogianlas todas, las cuales comian aquellos alfaquies y señores y principales, y los vestidos bailaban ansí todo aquel dia, y hacianse aquel dia otra mayor y nunca oida crueldade, y era que en aquellos seis palos que en la viglia de la fiesta habian levantado en alto, ataban aspados seis cautivos de guerra, y estaban debajo á la redonda mas de dos mil hombres y muchachos con flechas y arcos, y estos, en bajándose los que los habian ido á atar, disparaban en ellos muchas frechas, y así asaeteados medio muertos, dejábanlos caer de aquel altura, y del grande golpe que daban, se machucaban y quebrantaban los huesos, y luego les daban la tercera muerte sacrificándolos y sacándoles los corazones, y arrastrándolos y desviándolos de allí, la cuarta crueldade era degollarlos y cortarlos las cabezas, las daban á los alfaquies, y los cuerpos llevaban como carneros para los señores y principales, y otro dia con aquel convite hacian tambien fiesta”(34).

Anualmente, eram degoladas crianças ao deus da água, Tlaluc: "Una vez en al año, cuando ya estaban salidos de un palmo sus panes en sus labranzas, en los pueblos que habia señores y principales, que á la casa de cada uno de estos llaman tecpan, que quiere decir palacio, sacrificaban un niño é una niña de edad de tres ó cuatro años, que estos eran hijos de principales, no esclavos, y esto hacian en el monte, á honra de un demonio que se llamaba Tlaluc, que decian ser dios del agua y les daba la pluvia, y á este la pedian en habiendo falta de agua: estos niños inocentes no les sacaban el corazon, sino degollábanlos, y envueltos en mantas ponianlos en una caja de piedra, á honra de aquel demonio Tlaluc. Este era tenido en toda la tierra por muy principal dios, y su principal templo era en Tezcuco, juntamente con los dioses de México, los cuales templos eran más altos y mayores de toda la tierra, y más que los de México"(35).

No dia de Atemuztli um menino e uma menina eram afogados: "El dia de Atemuztli ponian muchos papeles pintados y llevábanlos á los templos de los demonios, y ponian ulli, que es una goma de un árbol que se halla en tierra caliente, al cual punzándole salen unas gotas blancas, y ayuntando lo uno con lo otro, tórnase negro, casi como pez blanda, y de esto hacen las pelotas con que juegan, que saltan más que las pelotas de viento de Castilla, aunque es más pesado; que salta tanto, que parece que tiene dentro azogue.(...) y entonces tambien salian de México, y llevaban en una canoa, que es como barco largo, un niño y una niña, y en medio de la laguna de México, echándolos en el agua los ofrecian al demonio, sumerjiéndolos con barco y todo"(36).

No dia de Tozoztli, quatro crianças escravas, entre cinco e sete anos, eram enterradas em oferenda a Tlacuc, deus da água. Motolinía fala também da origem do termo papa, empregado para denotar os grão-sacerdotes do sacrifício: "En este dia, cuando ya los panes estaban hasta la rodilla de alto, repartian y echaban pecho de que compraban quatro niños esclavos, de edad de cinco hasta siete años, y sacrificábanlos á Tlacuc, dios del agua, y ponianlos en una cueva, y cerrábanla hasta otro año, que hacian lo mesmo. Este sacrificio de inocentes tuvo principio de un tiempo que estuvo cuatro años que no llovió ni apenas

(34) Ibidem, p. 62-63.

(35) Ibidem, XX, p. 63.

(36) Ibidem, p. 63-64. 
quedó cosa verde, y por aplacar al demonio del agua, su dios Tlacuc, y porque lloviese, le ofrecian aquellos cuatro niños; y así el que no podia dar el agua ni era suya, la vendia por sangre de inocentes. Estos ministros ó carniceros del demonio, que en su lengua, como está dicho, se llama tlenamacaque, que eran los mayores sacerdotes de los ídolos, á manera de nazareos criaban unos cabellos muy grandes, y muy feos y sucios, que nunca los cortaban, ni lavaban ni peinaban, y así andaban engradejados, y ellos que muchas veces se tiznaban de negro, que no solamente parecian ministros del demonio, mas ese mesmo demonio. Aquella cabellera que criaban llamaban nopapa, que quiere decir mis cabellos, mopapa, tus cabellos, ypapa sus cabellos, topapa nuestro cabellos, etc., é de este nombre de los cabellos tomaron algunos españoles este vocablo de papa, y llamáronlos papas, y en buen romance se podian llamar verdugos crueles del demonio"(37).

No dia de Tititlh, festejavam com danças e sacrificavam cativos: "A reverencia de este demonio bailaba toda la gente dos dias con sus noches, y entonces sacrificaban los cabtivos en guerra tomados de muy lejos, que segun dicen los mexicanos, algunas provincias tenian cerca de sí de enemigos y de guerra, como era Tlaxcala, Huexucinco y Cholollan, que mas las tenian para ejercitarse en la guerra, y tener de do haver cabtivos para sacrificar, que no para pelear y acabarlos de sujetar. Las otras provincias tenian lejos, á do á tiempos ó una vez en el año hacian guerra, como era Michuacan, Pánuco, Tecoantepec, etc. De estas traian tambien muchos cabtivos, y en este dia sacrificaban de estos y no de otros, ni esclavos"(38).

Motolinía se refere à forte dissensão entre as tribos rivais, que as punha num permanente estado de alerta: "Sin las fiestas ya dichas, habia otras muchas, en diversas tierras, provincias y pueblos, en especial en Taxcalla, Huexucinco, Chololla, que eran señoríos por sí. En todas estas provincias adoraban un dios y lo tenian por principal, el cual nombraban por tres nombres, conviene á saber, Camaxtle, y de este usaban más en Tlaxcalla, y Huexucinco: llamábase ansimismo Quizalcovatlh, y en este nombre se usaba mucho en Chololla: tambien le llamaban Mixcovatlh. Los antigos que estas provincias poblaron fueron de una generacion, y como eran parientes, tambien muy amigos; pero despues que se multiplicaron, hicieron provincias distintas. Habia entre ellos muchas veces grandes guerras y defensiones. En estas provincias se hacian muy grandes sacrificios y crueldades, porque como todos estaban cercados de provincias subjetas á México, sus enemigos, arrimábanse mas al sacrificio y oblacion, y tambien entre sí mesmos eran las mayores guerras y más continuas, y habia entre ellos hombres de buenas fuerzas, en especial en Tlaxcalla, que es la mayor provincia de estas, y de gente harto guerrera, y es de las enteras y grandes provincias y bien poblada de la Nueva España. Estos de la provincia tenian por costumbre en sus guerras no solo defenderse y ofender y matar, pero cautivar para llevar á sacrificar á los templos de sus ídolos, y por esto en la guerra arremetian y abrazábanse con el que podian, y sacábanlo y atábanlo cruelmente para llevarle, y esta era costumbre general en toda la tierra, en que se mostraban y señalaban entre ellos los valientes hombres. Estos tenian otras fiestas por sí en muchos dias del año, y con muchas cerimonias y crueldades que no me recuerdo bien para escribir la verdad, aunque moré allí seis años y oí muchas 
cosas, pero ne me informaba para las escribir. En Tlaxcalla habia muchos señores y principales y mucho ejercicio de guerra, y tenian siempre como gente de guarnicion, y todos los que tomaban, demas de muchos esclavos, morian en sacrificio, y lo mismo en Huexucinco y Chololla, y á esta Chololla tenian por gran santuario, como otra Roma, á do habia muchos tiemplos del demonio, y dijéronme habia mas de trescientos y tantos, como dias hay en el año, é yo ví muchos, pero nunca los conté, y ansí tenia muchas fiestas en el año, y algunas de ellas venian de muy lejos, como de Cempualla, que es á la costa, cuarenta leguas de camino, y cada provincia tenia sua salas y casas dentro en Chololla, donde se aposentaban”(39).

Em Teuacan, Teutitlan e Cuzcatlan, províncias de fronteira, além dos sacrifícios, tinham o cuidado em cortar e fazer perfurações no órgão sexual: "En Teuacan y en Teutitlan y en Cuzcatlan, que eran provincias de frontera, que por muchas partes tenian guerra, tambien hacian muy crueles sacrificios de los cautivos y esclavos, y en sí mesmos cortaban y hendian el miembro de la generacion entre cuero y carne, y hacian tan grande abertura, que por allí pasaba una soga tan gruesa como el brazo, y de largo segundo la devocion del penitente, unas de diez brazas, y otras de quince, y otras de veinte, é si alguno desmayaba de aquel cruel desatino, decian que aquel poco ánimo era por haber pecado y allegado á mujer; ca estos que hacian este desatinado sacrificio eran mancebos por casar"(40).

As cabeças dos tomados em guerra e sacrificados eram escalpadas, e as caveiras expostas em estacas: "Las cabezas de los que sacrificaban, en especial de los tomados en guerra, desollaban, y si eran señores ó principales los ansí tomados, desollábanlas con sus cabellos, y sacábanlas para las guardar. De estas muchas al principio, y si no fuera porque tenian algunas barbas, nadie creyera sino que eran rostros de niños, y causábalo esto estar como estaban secas; e las calabernas ponian en unos palos que tenian levantados cerca de los templos del demonio, de esta manera, que levantaban diez y seis ó veinte palos, ó mas ó menos, de cuatro ó cinco brazas en alto, apartado uno de otro obra de una braza, y todos llenos de agujeros, y tomaban las cabezas horadadas por las sienes, y hacian unos sartales de ellas en otros palos delgados, y ponianlos en los agujeros que estaban en los palos ó vigas levantados, y ansí tenian alli de quinientas y ochocientas y más de á mil calabernas y más; y cayéndose algunas, ponian otras, porque valian muy barato é poco precio los muertos, $\mathrm{y}$ en tener sus templos tan adornados, mostraban ser grandes hombres de guerra $\mathrm{y}$ sacrificio" $^{(41)}$.

Durante a festa ao deus Camaxtle, no princípio de março, e particularmente no dia de Teuxiuitl, festejado a cada quatro anos, o mais velho dos sacerdotes ditos Achcauhtin “predicava y exhortava á todos los otros, y les decia: 'Hijos mios, ya es llegado el año de nuestro dios y señor; esforzaos á le servir y hacer penitencia, y el que se hallare flaco y sin espíritu, sálgase de aquí en cinco dias, y si se saliere á los diez y dejare la penitencia, este tal será tenido por no digno de la casa de dios, y de la compañia de sus servidores, y será privado, y tomarle han cuanto en su casa tiene.' Allegado al quinto dia, levantábase el mesmo viejo Achcauhtli, que en nuestra lengua quiere decir hermano mayor, y decia: ‘ ¿Están

\footnotetext{
(39) Ibidem, p. 67-68.

(40) Ibidem, p. 69.

(41) Ibidem, 26, p. 72.
} 
aquí todos?' Y respondian 'sí, ó 'falta uno ó dos', que pocas veces faltaban. Luego iban todos á una gran sierra, que está de aquí cuatro leguas de gran subida de cuesta la mitad del camino, y un poco antes quedábanse todos orando un poco más abajo de lo alto de la cuesta, y el principal Achcauhtli subia arriba do estaba un templo de la diosa Matlalcueye, y ofrecia allí chalchivitl, que son piedras de género esmeraldas, y preciadas, y plumas verdes grandes, que se llaman quetzalli, y mucho papel é incienso de la tierra, rogando con aquella ofrenda al señor Camaxtle y á Matlalcueye, les diese esfuerzo para comenzar el tiempo de su ayuno y acabarlos fuerzas para hacer penitencia.” De volta à cidade, juntavamse-lhes outros "que estaban repartidos por la tierra, y en otros templos, y traian muchas cargas de palos tan largos como el brazo y tan gruesos como la muñeca, y ponianlos en el principal templo de Camaxtle" ${ }^{(42)}$. Ao fim do período de jejum e pequenos sacrifícios, depois de ter suas línguas talhadas por navalhas, perfuravam-nas, o achcauhtli com "cuatrocientos y cinco palos" e "los otros tambien viejos y de fuerte ánimo sacaban otros cada cuatrocientos y cinco; otros no tan antigos sacaban trescientos de aquellos palos, que eran tan gruesos como el dedo pulgar del pié, y otros de tanto gordor cuanto pueden abrazar los dos dedos de la mano, el del pulgar y el del señalar: otros más mozos sacaban doscientos”(43). Esses paus ensanguentados eram oferecidos ao ídolo Camaxtle. Oitenta dias passados, em jejum parcial, proibidos de comer ají ou chilli, sem tomarem banho e sem se deitarem com suas mulheres, mas livres para comer carne, e conduzindo por meio outras cerimônias e rotinas, começava o sacrifício dos tomados em guerra. Uma cerimônia digna de atenção é esta descrita por Motolinía: "Antes de la fiesta, cuatro ó cinco dias, aderezaban todos los templos y salas de sus dioses, y encalaban lo desollado de ellos, y el tercero dia antes, pintábanse los achcauhtin unos de negro, y otros de blanco, y otros colorados, ó azul, ó verde, etc, y luego á las espaldas de la casa ó templo principal del demonio bailaban un dia entero. Luego vestian la estatua de su dios Camaxtle, que era de tres estados de altura, como arriba está dicho, y tenian un ídolo pequeño que decian haber venido con los viejos primeros que poblaron esta tierra: este ídolo ponian junto de la gran estatua de Camaxtle, y teníanle tanta reverencia y temor, que no le osaban mirar; aunque delante de él sacrificaban codornices, no usaban levantar los ojos á le ver. Aquí ofrecian al demonio despues de haber vestido las vestiduras é insignias del dios de Chololla, que llaman Quetzalcouatl ${ }^{(44)}$ : este decian ser hijo del mesmo Camaxtle, las cuales vestiduras traian los de de Chololla, que

\footnotetext{
(42) Ibidem, cap. 27, p. 74-75.

(43) Ibidem, p. 76.

(44) Em sua Historia eclesiástica indiana, p. 146, Mendieta diz que Quetzalcouatl é filho de Iztacmixcohuatl com Chimalmatl e que "salió hombre honesto y templado, comenzó á hacer penitencia de ayuno y disciplinas, y á predicar (segun se dice) la ley natural: y así enseñó por ejemplo y por palabra el ayuno, en esta tierra antes no usado, sino que desde este tiempo comenzaron algunos á ayunar, y despues se fué aumentando el uso del ayuno, que guardaban estos indios en su infidelidad con excesivo rigor. Este Quetzalcoatl no fué casado, antes dicen que vivó honesta y castamente. Él dicen que comenzó el sacrificio de sacar sangre de las orejas y de la lengua, no por servir al demonio (segun se entendia), mas por penitencia (aunque necia) contra el vicio del oir y hablar, y despues el demonio lo aplicó á su culto y servicio. A este Quetzalcoatl tuvieron los indios de esta Nueva España por uno de los principales de sus dioses, y llamáronle dios del aire, y por todas partes le edificaron templos, y levantaron su estatua, y pintaron su figura. Mas es de saber, que no todos los indios de las provincias de esta Nueva España concuerdan en decir que este fué su origen y dependencia, antes en diversos lugares se hallaron sobre esto diversas opiniones.” Robelo, em seu Diccionario. Op. cit., p. 47 ss., trata extensamente do assunto, trazendo as diferentes versões que disputam a explicação das características desse deus.
} 
está de aqui cinco leguas pequeñas, para esta fiesta; y esto mesmo hacian los de Tlaxcalla, que llevaban las insignias de su demonio á Chololla, cuando allá se hacia su fiesta, las cuales eran muchas y se las vestian con muchas cerimonias, como hacen á nuestros obispos cuando se visten de pontifical"(45).

Por fim, se dava o sacrifício dos prisioneiros, em honra de Camaxtle e de outros deuses. Segundo Motolinía, no templo de Camaxtle matavam 405; no bairro de Tepeticpac, 56. No total, somando-se os dos outros 28 povoados da província, eram 800 os mortos num só dia. Depois, "llevaba cada uno los muertos, segun los vivos que habia traido, dejando alguna parte de aquella carne humana á aquellos achcauhtin ó ministros, y entonces todos comenzaban á comer su chile ó ají con de aquella carne, é hacian de la manera que se dice se hacia en Cuauhtitlan”(46).

Em outras festas do ano, especialmente no fim dos meses, de vinte dias cada um, tinham "muchos ritos y sacrificios y homicidios, semejables á los que hacian en las otras provincias de México y en esta tambien excedian en esta provincia á las otras, que mataban por año más niños é niñas que en otra parte, en lo que hasta agora he sabido; y estos inocentes se sacrificaban á los dioses del agua, que eran Tlaluc y Matlalcueye y Xuchiquetçal: tambien quemaban en fuegos, en otras fiestas del año algunos, como está dicho en el capítulo décimonono, y en otra fiesta levantaban uno en una cruz atado, y allí le asaeteaban: á este le ponian muy alto; y á otro dia, tambien de fiesta, ataban á otro de la mesma manera, algo mas bajo, y con unas varas de palo de encina de una braza, lo mataban muy cruelmente con aquellas varas, que estaban muy agudas, como acañaverado, y casi estas mismas ceremonias y ritos usaban y guardaban en las provincias ya dichas de Huexutcinco, Tepeyacac, y Zacatlan y Cazotlan en la solenidad de estas fiestas.

"Otro dia del principio de los meses, desollaban dos mujeres, despues de sacrificadas, y vestíanse los cueros de ellas dos mancebos de aquellos achcauhtin, buenos corredores, y ansí vestidos andaban por el patio y por el pueblo, tras los señores y principales, que en esta fiesta se vestian mantas buenas y ricas y limpias, y corrian em pos de ellos, y al que alcanzaban tomábanle sus mantas, y ansí con este juego de tanta alegria se fenecia esta fiesta”(47).

Os trechos de cronistas que exibimos, com relatos sobre a morte ritual entre os astecas e povos vizinhos, fazem parte, juntamente com os códices pictóricos e ideográficos, com a estatuária e com as descobertas arqueológicas, da coleção de documentos disponíveis sobre os inícios da conquista da América. Em conjunto, eles contêm os primeiros registros que tornam verossímil qualquer tentativa de dar conta dos acontecimentos daquele tempo. Em torno deles, existe mesmo uma ampla tradição exegética, que a cada época cresce e se enriquece. Isto, porém, não basta para evitar as discussões em tons mais cáusticos em tor no da sua validade documental e, portanto, da sua eficácia em produzir mais certezas do que dúvidas. De qualquer modo, insistimos que, para uma correta avaliação do sacrifício americano, enquanto fenômeno relevante do passado religioso e político dos povos que o

(45) MOTOLINíA. Op. cit., p. 77.

(46) Ibidem, p. 78.

(47) Ibidem, cap. 28, p. 79-80. 
praticaram por séculos antes da chegada dos europeus à América, esses relatos são incontornáveis. Por outro lado, é preciso reconhecer que a variedade dos meios e objetivos que o fenômeno apresentou no tempo e no passado, incorporando-se ao dia a dia dos mexicanos, fazem aumentar a insegurança quanto à nossa capacidade de esclarecer o seu significado real, qualquer que seja o meio de análise à disposição. Sobre essa questão e outras paralelas voltaremos a falar num próximo trabalho ${ }^{(48)}$. Por ora, fiquemos com os testemunhos dos que presenciaram as cerimônias, acompanharam os rituais e se tornaram a primeira memória literária dos fatos.

\section{REFERÊNCIAS BIBLIOGRÁFICAS}

BIBLIOTECA DE AUTORES ESPAÑOLES. Historiadores primitivos de Indias. Madri, 1852. v. I e II.

BURKERT. The problem of ritual killing. In: HAMERTON-KELLY, G. (ed.). Violent origins. Stanford: Stanford University, 1987.

CASTILLO, Bernal Díaz Del. Verdadera historia de los sucesos de la conquista de la Nueva-España. In: VEDIA, Enrique de (ed.). Biblioteca de autores españoles, historiadores primitivos de Indias. Madri, tomo $2,1853$.

CLAVIGERO, F. S. The history of Mexico. Collected from Spanish and Mexican historians, from manuscripts, and ancient paintings of the Indians. Trad. de Charles Cullen. Illustrated by Charts, and other Copper-Plates. To which are added Critical Dissertations on the Land, Animals and Inhabitants of Mexico. Richmond: W. Prichard, 1806.

COMPANHEIRO DE HERNAN CORTÉS. O conquistador anônimo. In: Narratives of some things of new spain and of the great city of temestitan Mexico. Trad. de M. H. Saville. New York, 1917.

CORTÉS, F. Cartas de relación. México: Porrúa, 2005.

DURÁN, Diego. Historia de las Indias de Nueva-España y islas de tierra firme. México: Porrúa, 1867.

DUVERGER, Christian. La flor letal economía del sacrificio azteca. México: Fondo de Cultura Económica, 1993.

ERNOUT, A.; MEILlET, A. Dictionnaire étymologique de la langue latine. 3. ed. Paris: Klincksieck, 1951.

FOWLER, W. Warde. The religious experience of the roman people from the earliest times to the Age of Augustus. Londres: MacMillan, 1911.

KLUGE, F. Etymologisches wörterbuch der deutschen sprache. Trübner: Strasburg, 1905.

LÍVIO, Tito. Oeuvres. Paris: Puf, 1869.

MENDIETA, Jerónimo de. Historia eclesiástica indiana. México: Porrúa, 1870.

MOTOLINÍA (Toribio de Benavente). Memoriales de fray Toribio de Motolinía. México: 1903.

(48) Como pretendemos traçar, em três ensaios, sendo este o primeiro, um painel sobre a prática do sacrifício entre astecas e incas, seguido duma reflexão tomando por base os dados recolhidos, deixaremos para discutir em outra oportunidade os reparos feitos aos cronistas, sobretudo pelos adeptos do método da antropologia e da psicologia. 
POKORNY, J. Indogermanisches etymologisches wörterbuch. Berna: Francke, 1959.

ROBELO, Cecilio A. Diccionario de mitología Nahoa. In: Anales del Museo Nacional de México, n. 5, 1908.

VARRÃO. De lingua latina quae supersunt. Leipzig: Teubner, 1910.

WALDE, A.; HOFMANN, J. B. Lateinisches etymologisches wörterbuch. Heidelberg, 1938.

WISSOWA, G. Religion und kultus der Römer. Munique: Witke, 1902. 